Bangladesh Journal of Neuroscience 2012; Vol. 28 (1) : 10-15

\title{
Efficacy of Local Corticosteroid in Idiopathic Carpal Tunnel Syndrome: A Randomized Controlled Trial
}

\author{
ANIS AHMED ${ }^{1}$, MD. RAFIQUL ISLAM ${ }^{2}$, HASAN ZAHIDUR RAHMAN ${ }^{3}$, MD. MONIRUZZAMAN \\ BHUIYAN $^{3}$, SUKUMAR MAJUMDER ${ }^{4}$, PROVAT KUMAR SARKER ${ }^{5}$, \\ MD. ALIMUR REZA ${ }^{6}$, HASAN IMAM ${ }^{7}$
}

\begin{abstract}
Background: Carpal tunnel syndrome (CTS) is a common health problem in Bangladesh especially among women. It causes significant morbidity and reduces work output in affected patients. There are few treatment options available like oral steroid, steroid injection, UST, surgical treatment etc. Considering the cost, time and consequence of surgery, short term nonsurgical management is desirable e.g. local steroid injection in the affected limb. Therefore a comparative analysis is necessary to understand the efficacy of local steroid injection. Objective: To evaluate the efficacy of local corticosteroid injection in the treatment of idiopathic carpal tunnel syndrome. Methods: 60 idiopathic CTS patients divided into two groups by randomization. One group received Inj. Triamcinolone $30 \mathrm{mg}$ close to carpal tunnel and other group received oral steroids. Efficacies of treatmemt were compared in between groups. Result: The mean age of two groups were $37.5 \pm 10.5$ and $37.0 \pm 10.24$ years respectively $(p=0.272)$ and Majority of the patients in both treatment groups $(76.7 \%$ in local steroid and $80 \%$ in oral steroid groups, $p=0.754$ ) were female. Relief from tingling sensation and nocturnal awakening was higher in the steroid injection receivers $(100 \%$ and $86.7 \%$ respectively) than that in the oral steroid receivers (6.9\% and $3.4 \%$ respectively) during evaluation of outcome at the end of 3 month. End point treatment shows that none but SNAP at wrist in the local steroid group improved significantly better than that in the oral steroid group (16.2 \pm 10.5 vs. $12.4 \pm 6.3, p=0.039)$. No major side effects occurred in local steroid group except depigmentation in injected area $3(10 \%)$ cases. Conclusion: It may be concluded that local steroid injection is an effective treatment of idiopathic carpal tunnel syndrome. But long-term efficacy of steroid injection remains uncertain.
\end{abstract}

Keyword: Carpal Tunnel Syndrome, Corticosteroid, Electrophysiology

\section{Introduction}

Now-a-days Carpal tunnel syndrome (CTS) is an emerging health problem in Bangladesh especially among middle and old age female population. It is the compression of the median nerve at the wrist (carpal tunnel) in absence of an obvious injury, trauma or surgery which causes significant morbidity and reduces work output in affected patients. Many patients have to change jobs or modify activities to decrease their symptoms ${ }^{1,2}$. Women are three times more likely to develop CTS than men. The prevalence of CTS in general Western European population has been estimated to be at $3 \%$ to $5.8 \%$ for women and $0.6 \%$ to $2.1 \%$ for men ${ }^{3,4}$. There are many therapeutic approaches for CTS; among them some are conservative, including avoiding excess use of hand, use of splint, oral steroid, local steroid, diuretics, oral pyridoxine therapy UST etc. Regarding non-conservative measures, surgery is the approach of choice.

Patients with CTS should avoid repetitive wrist and hand motions and if possible, should not use

1. Resident, Department of Neurology, Bangabandhu Sheikh Mujib Medical University, Dhaka.

2. Professor, Department of Neurology, BSMMU, Dhaka.

3. Associate Professor, Department of Neurology, BSMMU, Dhaka.

4. Registrar, Department of Neurology, Rangpur Medical College \& Hospital.

5. Medical Officer, Neuroscience Institute, Dhaka.

6. Senior Assistant Manager, Medical Department, Beximco Pharmaceuticals Limited.

7. Medical Officer, Department of Medicine, BSMMU, Dhaka. 
vibratory tools ${ }^{5}$. Ergonomic measures to relieve symptoms depend on the motion that needs to be minimized. Patients, who work on computers, may benefit from improved wrist positioning or the use of wrist support. In addition to wrist splinting, conservative treatments includes oral corticosteroid therapy and local steroid injections. Surgical decompression of median nerve at carpal tunnel is costly and has limited access. Oral corticosteroid has no or minimum evidence of long term efficacy rather than high dose oral corticosteroid use for prolonged period has many adverse effects. Local corticosteroid injection at carpal tunnel in patients with CTS improve symptoms in more than $75 \%$ of cases and has been superior to oral corticosteroid in randomized clinical trials. Wong et al. ${ }^{6}$ have reported that local triamcinolone $30 \mathrm{mg}$ not only give symptomatic relieve but also improve distal motor $(D M L)$ and sensory (DSL) latencies of the median nerve. Most of the respondents maintained their response twelve months without any additional therapy.

So, considering the cost, time and consequence of surgery, short term nonsurgical management is desirable e.g. local steroid injection in the affected limb. Therefore a comparative analysis is necessary in this arena. As far as my knowledge goes previous studies on CTS have not focused on this particular issue in Bangladesh. If it is proved that this type of maneuver is effective for the patient in relief of symptoms, then it will be really helpful for the clinicians, researchers as well as health planners to contribute towards better management of CTS.

\section{Objectives}

- To evaluate the efficacy of local corticosteroid injection in the treatment of idiopathic carpal tunnel syndrome.

- To determine the period of symptom relief following corticosteroid injection into the carpal tunnel.

- To determine the extent of relief of symptoms.

- To compare the efficacy of local corticosteroid with oral corticosteroid in reducing symptoms by symptoms severity score and functional status score.
- To find out electrophysiological changes before and after treatment in both groups by functional status score.

- To determine the side effects of both modalities of treatment.

\section{Materials \& Methods:}

This was a randomized controlled clinical trial carried out in the Department of Neurology, Bangabandhu Sheikh Mujib Medical University (BSMMU) starting from July 2008 to June 2010. Patients attending the outpatient of Department of Neurology, BSMMU, designated as clinically suspected CTS and established by electrophysiological parameters and treated in two groups. One group received Injection Triamcinolone $30 \mathrm{mg}$ close to carpal tunnel once in a month and other group received oral steroids for one month. Patients who are idiopathic and age in between 12 to 70 years were included in the study. Patients with symptoms less than 3 months and who has CTS-like condition such as cervical radioculopathy, proximal median neuropathy or significant polyneuropathy and with hypothyroidism, diabetes mellitus, pregnancy, cognitive impairment, vibrating tool users, muscle wasting and with recent peptic ulcer disease or history of steroid intolerance were excluded from the study. Selected subjects were randomly assigned to local steroid injection and oral steroid group. All relevant information from history, clinical examination and investigations were collected in a semi-structured data collection sheet. Collected data were processed and analyzed by using computer based software, statistical package for Social Science (SPSS).

\section{Observation \& Results}

Among total 60 cases of carpal tunnel syndrome majority of the patients in both treatment groups (76.7\% in local steroid and $80 \%$ in oral steroid groups) were female $(p=0.754)$. Age distribution was almost similar in both the treatment groups and mean age of the local steroid and oral steroid groups were $37.5 \pm 10.5$ and $37.0 \pm 10.24$ years respectively $(p=0.272)$. Distribution of the patients by affected hands between groups is more or less similar $(p=0.575)$. Ninety percent of the patients of local steroid injection group had been suffering 


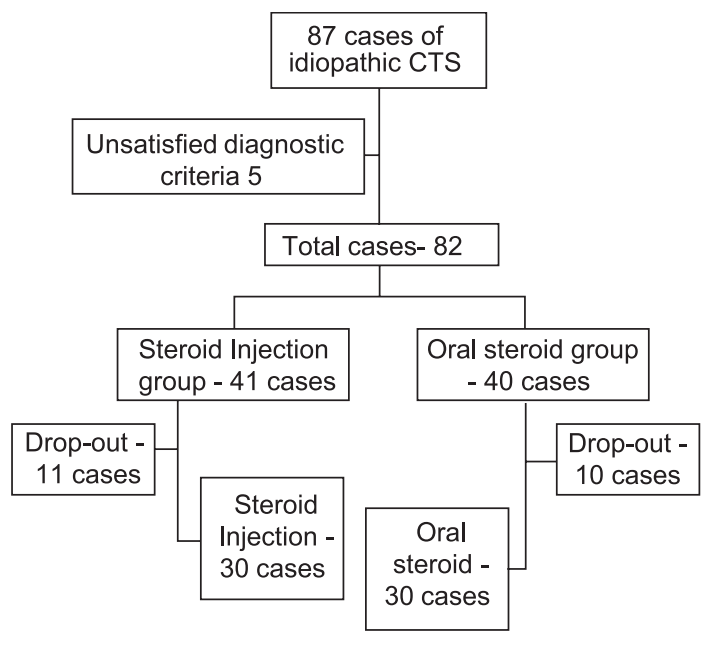

Fig.-1. Flow diagram of the subject progress through the phases of the study. A total of 87 cases clinically diagnosed a idiopathic CTS were selected for the study. Among them 82 cases satisfied diagnostic criteria. Then 41 cases randomly selected for local steroid injection and 40 for oral steroid. During follow-up of three months 11 cases who took injection steroid and 10 cases who took oral steroid were dropped out. So, finally 30 cases of both groups were studied.

from Carpal Tunnel Syndrome for $>6$ months at entry compared to $66.7 \%$ of the oral steroid group $(p=0.002)$. Comparison of clinical characteristics of the patients between groups shows that tingling was invariably present in both the treatment groups $(p=0.029)$. Seventy percent of the local steroid injection receivers and $53.3 \%$ of the oral steroid receivers had persistent numbness $(p=0.31)$. No significant difference was observed between the groups in terms of nocturnal increase in symptoms with consequent awakening $(p=0.500)$, Phalen's maneuver $(p=0.063)$ and Tinel's sign $(p=0.500)$.
Symptoms severity score and functional status score were also identically distributed between the groups ( $p=0.066$ and $p=0.110$ respectively). All the measures of electrophysiological variables pertaining to median nerve before intervention are analyzed and none of the variables but distal motor latency was observed to be significantly higher in the local steroid injection group compared to oral steroid group.

Evaluation of outcome at month 3 revealed that symptoms severity score and functional status score reduced significantly in both the study groups from their baseline figures $(p<0.001)$ (Table I). Regarding electrophysiological parameters in local steroid group DML and DSL at wrist were reduced, while CMAP and SNAP were increased significantly at month 3 from their baseline figures $(p<0.001, p$ $<0.001, p<0.001 p=0.009$ respectively) (Table II). In oral steroid group no significant change was noted in terms of any of the 5 electrophysiological variables ( $p>0.05$ in each case) (Table II).

Evaluation of outcome 3 months after intervention demonstrates that $100 \%$ of local steroid injection receivers got relief from tingling sensation in the affected hand $(p=0.22)$ as opposed to only $6.9 \%$ of the oral steroid receivers $(p<0.001)$. Relief from nocturnal awakening was also appreciably higher in the steroid injection receivers (86.7\%) than that in the oral steroid receivers (3.4\%). Symptoms severity score and functional status score were also at much lower level in the former group than those in the latter group $(p<0.001$ and $p<0.001$ respectively). Relief of numbness was considerably higher in the former group than that in the latter group, though the difference was not statistically significant $(p=0.153)$ (Table III).

Table-I

Changes in clinical scores in both groups following intervention

\begin{tabular}{|c|c|c|c|c|c|c|}
\hline \multirow[t]{2}{*}{ Scores } & \multicolumn{3}{|c|}{ Local Steroid Injection } & \multicolumn{3}{|c|}{ Oral Steroid } \\
\hline & $\begin{array}{c}\text { Before } \\
\text { intervention }\end{array}$ & $\begin{array}{c}\text { After } \\
\text { intervention }\end{array}$ & p-value ${ }^{\#}$ & $\begin{array}{c}\text { Before } \\
\text { intervention }\end{array}$ & $\begin{array}{c}\text { After } \\
\text { intervention }\end{array}$ & $p$-value \\
\hline & $(n=30)$ & $(n=30)$ & & $(n=30)$ & $(n=30)$ & \\
\hline Symptoms severity score ${ }^{i}$ & $26.8 \pm 4.5$ & $17.5 \pm 5.2$ & $<0.001$ & $31.4 \pm 3.9$ & $28.7 \pm 3.8$ & $<0.001$ \\
\hline Functional status score & $19.8 \pm 3.1$ & $12.5 \pm 3.6$ & $<0.001$ & $22.8 \pm 3.9$ & $19.6 \pm 3.8$ & $<0.001$ \\
\hline
\end{tabular}

'Data was analyzed using Paired t-Test and were presented as Mean \pm SD. 
Table-II

Changes in electrophysiological parameters in both groups following intervention Electrophysiological variablesLocal Steroid Injection Oral steroid

\begin{tabular}{lcccccc}
\hline & $\begin{array}{c}\text { Before } \\
\text { intervention } \\
(\mathrm{n}=30)\end{array}$ & $\begin{array}{c}\text { After } \\
\text { intervention } \\
(\mathrm{n}=30)\end{array}$ & P-value $^{\#}$ & $\begin{array}{c}\text { Before }^{\text {intervention }} \\
(\mathrm{n}=30)\end{array}$ & $\begin{array}{c}\text { After } \\
\text { intervention } \\
(\mathrm{n}=30)\end{array}$ & P-value $^{\#}$ \\
\hline DML $(\mathrm{ms})$ & $6.7 \pm 2.09$ & $5.9 \pm 1.53$ & $<0.001$ & $5.75 \pm 0.98$ & $5.64 \pm 1.0$ & 0.091 \\
$\mathrm{CMAP}(\mathrm{mV})$ & $7.5 \pm 2.4$ & $8.5 \pm 2.17$ & $<0.001$ & $8.10 \pm 3.04$ & $7.9 \pm 3.0$ & 0.122 \\
MNCV $(\mathrm{m} / \mathrm{s})$ & $50.5 \pm 3.7$ & $50.6 \pm 3.6$ & 0.69 & $50.78 \pm 3.97$ & $50.64 \pm 3.7$ & 0.273 \\
DSL at wrist $(\mathrm{ms})$ & $3.20 \pm 1.3$ & $2.7 \pm 1.1$ & $<0.001$ & $2.91 \pm 1.21$ & $2.9 \pm 1.2$ & 0.407 \\
SNAP at wrist $(\mu \mathrm{V})$ & $14.2 \pm 10.2$ & $16.2 \pm 10.5$ & 0.009 & $12.7 \pm 6.5$ & $12.3 \pm 6.3$ & 0.066 \\
\hline
\end{tabular}

\# Data were analyzed using Paired t-Test and were presented as Mean \pm SD.

Table-III

Clinical outcome 3 months after intervention between groups

\begin{tabular}{lccc}
\hline Outcome variables & \multicolumn{2}{c}{ Group } & p-value $^{\#}$ \\
\cline { 2 - 3 } & $\begin{array}{c}\text { Local } \\
\text { steroid } \\
\text { injection } \\
(\mathrm{n}=30)\end{array}$ & $\begin{array}{c}\text { Oral } \\
\text { steroid } \\
(\mathrm{n}=30)\end{array}$ & \\
\hline Relief of tingling $^{\dagger}$ & $30(100.0)$ & $2(6.9)$ & $<0.001$ \\
Relief of numbness $\#^{\text {Relief from nocturnal }}$ & $12(40.0)$ & $7(24.1)$ & 0.153 \\
awakening $^{\#}$ & $26(86.7)$ & $1(3.4)$ & $<0.001$ \\
Symptom severity score $^{\pi}$ & $17.5 \pm 5.26$ & $28.7 \pm 3.85$ & $<0.001$ \\
Functional status score $^{\Uparrow}$ & $12.5 \pm 3.6$ & $19.6 \pm 3.84$ & $<0.001$ \\
\hline
\end{tabular}

\# Data was analyzed using Ç2 Test; †Data was analyzed using Fisher's Exact Test;

II Data was analyzed using Student's t-Test and was presented as Mean \pm SD.

No major side effects occurred in local steroid group except 3(10\%) depigmentation in injected area. In oral steroid group $6(20 \%)$ nausea, 3 (10\%) epigastric pain, 1 (3.33\%) leg oedema, and $1(3.33 \%)$ raised blood pressure occurred.

\section{Discussion:}

Carpal Tunnel syndrome is a very common problem encountered in Bangladesh. This hospital based study and was carried out to see the efficacy of local steroid over systemic steroid. Age distribution was almost similar in both the treatment groups with peak age incidence being observed in between 3rd and 4th decades of life (43\%). Agarwal et al. ${ }^{7}$ observed the highest percentage $(51 \%)$ of both groups were $4^{\text {th }}$ decade of life. Majorities of the patients in both treatment groups $(76.7 \%$ in local steroid and $80 \%$ in oral steroid groups) were female. Padua et al. ${ }^{8}$ observed same in both groups (71\% in local steroid and $73 \%$ in oral steroid groups). It revealed that two-third cases of both groups had right hand affected and very few patients had both hands affected. Most of the studies including Shekhar et al. ${ }^{9}$ also found the same. Most of the patients had been suffering from Carpal Tunnel Syndrome for $>6$ months at entry which is also supported by other studies.

Comparison of clinical characteristics of the patients between groups shows that tingling was invariably present in both the treatment groups $(p=0.029)$. Seventy present of the local receivers and $53.3 \%$ of the oral steroid receivers had persistent numbness $(p=0.31)$. But evaluation of outcome 3 months after intervention demonstrates that $100 \%$ of local steroid injection receivers got relief from tingling sensation in the affected hand ( $p=0.22$ ) as opposed to only $6.9 \%$ of the oral steroid receivers $(p<0.001)$. This result is quite consistent with that of the study done by Agarwal et $\mathrm{al}^{7}$. Relief of numbness was also better for local steroid group as $40 \%$ compared to oral steroid group $24.1 \%$. But there was no significant difference in between groups regarding relieve of numbness. But Goyal et al. ${ }^{10}$ found significant difference regarding relief of numbness between local steroid group and oral steroid group. Relief from nocturnal awakening was appreciably higher in the steroid injection receivers $(86.7 \%)$ then that in the oral steroid receivers (3.4\%). There was significant difference between the groups. Singh 
et al. ${ }^{11}$ also found the significant difference between groups regarding Relief from nocturnal awakening. In this study it was revealed that symptom severity scale and functional status scale was significantly reduced after three months following intervention (In all cases $p<0.001$ ) in both groups. Shekhar et al. ${ }^{9}$ also found significant difference in both groups. From local steroid group DML (ms) and DSL W (ms), was reduced significantly after 3 months following intervention than before intervention. But in oral steroid group there is no significant difference between before and after intervention. Padua et al. ${ }^{8}$ also observed significant difference in local steroid group and no significant difference in oral steroid group regarding DML ( $\mathrm{ms}$ ) and DSL $\mathrm{W}(\mathrm{ms})$ in between before intervention and 3 months following intervention. On the other hand CMAP (mv) and SNAP W $(1 / 4 \mathrm{~V})$ was increased significantly from before intervention to three months following intervention in local steroid group. In oral steroid group those were not significantly increased before and after intervention. Padua et al. ${ }^{8}$ also observed significant difference in local steroid group and no significant difference in oral steroid group regarding CMAP (mv) and SNAP W $(1 / 4 \mathrm{~V})$. The study revealed that no major side effects occurred in local steroid group except depigmentation in injected area in $10 \%$ cases. But in oral steroid group nausea, epigastric pain, leg oedema, and raised blood pressure occurred. Agarwal et al. ${ }^{7}$ also found depigmentation in injected area in some patients in local steroid group and various types of side effects such as nausea, epigastric pain, leg oedema and hirsutism in oral steroid group.

Some wide variability in response to local steroid injection probably is due to the heterogeneity of the patients in terms of their symptoms, severity, functional impairment and natural history and outcome assessments. From all these discussion it appeared from our data, that relief of symptoms, will support the case for a policy of treating CTS patients with local corticosteroid injections rather than oral corticosteroid. This study showed a clear benefit from steroid injection versus oral steroid in the treatment of CTS. Steroid injection is a safe, easy to perform and effective short-term treatment in CTS.

In this study sample size was small due to time and resource constraint. Random sampling technique was also not followed. Single follow-up is another limitation of this study. It would have been better if multiple follow-up could have been done.

\section{Conclusion:}

It may be concluded that local steroid injection is an effective treatment of idiopathic carpal tunnel syndrome. But these studies have some limitations, i.e regarding long-term efficacy of steroid injection remains uncertain. In case of mild to moderate idiopathic carpal tunnel syndrome, every patient should be treated with local steroid injection and should be considered before surgical decompression. This study would stimulate the necessity of further study in a large scale in future; which may be helpful for clinicians, researchers, as well as health planners to contribute towards better management of CTS.

\section{References:}

1. Nancollas, M.P., Peimer, C.A., Wheeler, D.R. Long-term results of carpal tunnel release. Journal of Hand Surgery [British volume], 20:470-4.

2. Pinkman, J. Carpal tunnel syndrome impacts thousands and costs are shyrocketing. Occupational Health \& Safety. 1988; 57;523.

3. De, Krom, M.C.T.F., Kester, A., Knipschild, P. Risk factors for carpal tunnel syndrome. American Journal Epidemiology, 1990;132:1102-10.

4. Atroshi, I., Gummensson, C., Johnson, R. Prevalence of carpal tunnel syndrome in a general population. Journal of the American Medical Association 1999;282:153-8.

5. Stevens, J.C. The electrodiagnosis of carpal tunnel syndrome. Muscle Nerve, 1997;20:1477-86.

6. Wong, S.M., Hui, A.C.F., Tang, A. Local versus systemic corticosteroids in the 
treatment of carpal tunnel syndrome. Neurology, 2001;56:1565-7.

7. Agarwal, V. R., Singh, A., Sachdev. A prospective study of the long-term efficacy of local methyl prednisolone acetate injection in the management of mild carpal tunnel syndrome, Rheumatology, 2005; 44:647-650

8. Padua L, Giannini F, Girlanda P. Usefulness of segmental and comparative tests in the electrodiagnosis of carpal tunnel syndrome: the Italian multicenter study. Italian CTS Study Group. Ital J Neurol Sci. 1999; 20(5):315-20.
9. Shekhar S. and Bhaduri B. Sub-class Recognition from Aggregate Class Labels: Preliminary Results, International Conference on Tools with Artificial Intelligence (ICTAI), IEEE, 2008.

10. Goyal V, Bhatia M, Padma MV. Electrophysiological evaluation of 140 hands with carpal tunnel syndrome. J Assoc Physicians Ind 2001, 49: 1070-3.

11. Singh R, Gamble G, Cundy T. Lifetime risk of symptomatic carpal tunnel syndrome in Type 1 Diabetes. Diabet Med 2005;22:625-30. 